\title{
KEEPING UP WITH COMPLEXITY
}

\author{
Tore GULDEN and Kristin STØREN WIGUM \\ Oslo Metropolitan University
}

\begin{abstract}
As the global population increases exponentially, pressure on resources, new technology, and communication all affect and are affected in a strengthening recursive manner by the behaviour of the majority. Although design education programmes have adapted to some extent, designers generally lack the knowledge or methodology to keep up with society's increasing complexity. This paper describes our attempts to develop a master design programme for this complex world. On a chart describing our existing programme and a new programme called Design in Complexity, the horizontal axis represents the dimensions of experience and philosophy \& politics, and the vertical axis refers to materiality and relations \& systems. As additional sources of complexity, the work also refers to EU demands and UN strategies for academic research and development that emphasise grand challenges and megatrends in society. In discussing how product design can connect to larger themes and challenges through system-oriented design [1], we explore the context in which design performs. Rather than explaining design from a practical, theoretical, or idealistic point of view, we acknowledge that operating in a complex systemic network of relations means that complexity is a given [2]. For that reason, we emphasise systems literacy as a major competency for designers and the new pedagogical methods this demands. Rather than focusing on specialisms or products to be designed, Design in Complexity addresses design processes in terms of systems and connected understandings from which product and service concepts emerge, so facilitating ongoing programme adaptation and change.
\end{abstract}

\section{Keywords: Master programme, system-oriented design, educational approach, mega-trends}

\section{DESIGN EDUCATION: COLLAPSE THROUGH CERTAINTY}

Design education is rooted in cultural and language traditions that are largely inward-looking describe a reality within the discipline, making the design discipline difficult to change. Most educators and programme coordinators try to promote structural change, typically by introducing the latest technologies or by addressing defined societal problems, within the educational system in which they have always operated. In making such changes, educators commonly believe they are at the forefront of societal and environmental development and remain unaware that this belief in the certainty of their existing institutional and disciplinary reality is outdated and hinders holistic perspectives. These programmes teach knowledge and train students in methods and skills; by extension, they implant perspectives that are insufficient or maladjusted to the complexity of society and design work. In this way, design education is on a stable course towards collapse. That collapse can only be prevented by changes in systemic cognition [3] - that is, by accepting that the world is a continuously changing and complex arena for designers, that stable realities do not exist, and that ideology-driven design education promotes judgment, prejudice, and a desire to control [3]. One interesting question that arises, then, concerns how we are to understand and experience in a global context the systems we form part of as individuals and groups. These systems interconnect and influence each other, producing the "...changing complexity in which we live" that humans can never fully comprehend [4]. As we cannot fully foresee or regulate how systems function, or how they affect each other, designers must be aware of this ambiguity if they are to "regard situations without judgment, prejudice, or the desire to control" [2]. Accordingly, if designers approach systems with sufficient awareness and attention to this ambiguity, they can perform within them with the intelligence of wonder rather than stress and denial, becoming wiser and more systems-literate by accepting the surrounding complexity [2]. 
In this industrial and globalised postmodern society, design and engineering education typically trains students in processes related to increased sales, user experience, customer relations, production efficiency, and so on. These schools' philosophies have varying origins in art and craft orientations that emphasise form and material experimentation and industry-orientated schools emphasising mass production and commercial factors. Both types have changed with the introduction of environmental, societal, digital, and inclusivity issues. However, this incremental approach to change by adding and replacing courses is based on a belief in a continuing reality, and this outdated platform of methods, knowledge, and skills does not promote change in ideological philosophical, or epistemological stance because it looks inward to the tradition rather than outward to the context in which designs, and designers must perform. This lack of systemic cognition is especially problematic at a time of exponential and global change in terms of environment, consumption patterns, technology, and demography. These design problems and potentials are typically approached by using tools that fail to support understanding; and cannot be solved through form experimentation and inclusive approaches. In our teleological research and development of a design education that serves as a platform for continuous change and new philosophies and contexts, we do not attempt to describe or control what intelligence is. Rather, we aim to create a context in which systems continuously emerge, producing intelligence through wonder, holistic thinking, and implementation [5]. We aim to change the design education culture by changing the rules for rethinking design education [6], based on attention to system ambiguity in a complex world. This article describes how we changed the understanding of quality and context in design education and our work to develop an entirely new approach based on general systems theory. To that end, we address the conceptual background to developing a master in design based on systems theory.

\section{FROM INCREMENTAL IMPROVEMENT TO RADICAL CHANGE}

The product design profession builds on several other disciplines, including sociology, art, economics, marketing, engineering, and anthropology; in other words, it is by its nature interdisciplinary. Design researchers in particular focus on emerging problem areas in other fields such as engineering, construction, and health; to that extent, design is also transdisciplinary. As opposed to artists or engineers, then, designers' work focuses on the user or receiver, creating a product or service that takes account of needs, potential gains, culture, economy, and so forth. In addition, they must abide by external frameworks, rules, and regulations as defined by governments, global agreements, and principles and goals for sustainable development. Accordingly, the design profession can be said to build their competence on a broad spectrum of theory and contact with the people for whom they create services and tangible products. We used visual mapping to capture the intended competences and emphasis of our own master programme in the wider context of radical educational change [7], positioning education within an axonometric diagram specified by various dimensions. A major function of this diagram was to exclude in-house expertise, traditions, and the existing profession. The four different dimensions in the diagram instead relate to material and non-material factors in design, including relations between people and between people and products and services, which in all instances provide the impetus for designers to act. These dimensions were chosen to represent the twoway influence between designers and individual users (experience), society in general (political/philosophical), design skills and knowledge in relation to tangible products and sustainability (materials), and the context in which all of these perform (complexity/systems relations). The axes are not dichotomous but overlap and may occur together. To begin, we explored our own existing bachelor and master programmes in relation to these four dimensions by placing the focal point of the programme represented by the centre of the red circle; the breadth of student praxis is indicated by the periphery of the red circle. This exploration was based on manual mapping of bachelor and master theses. Next, we assigned new positions to the two programmes and defined an area that seemed a natural destination for programmes that would prepare students for the new context in which they must perform (Figure 1). 


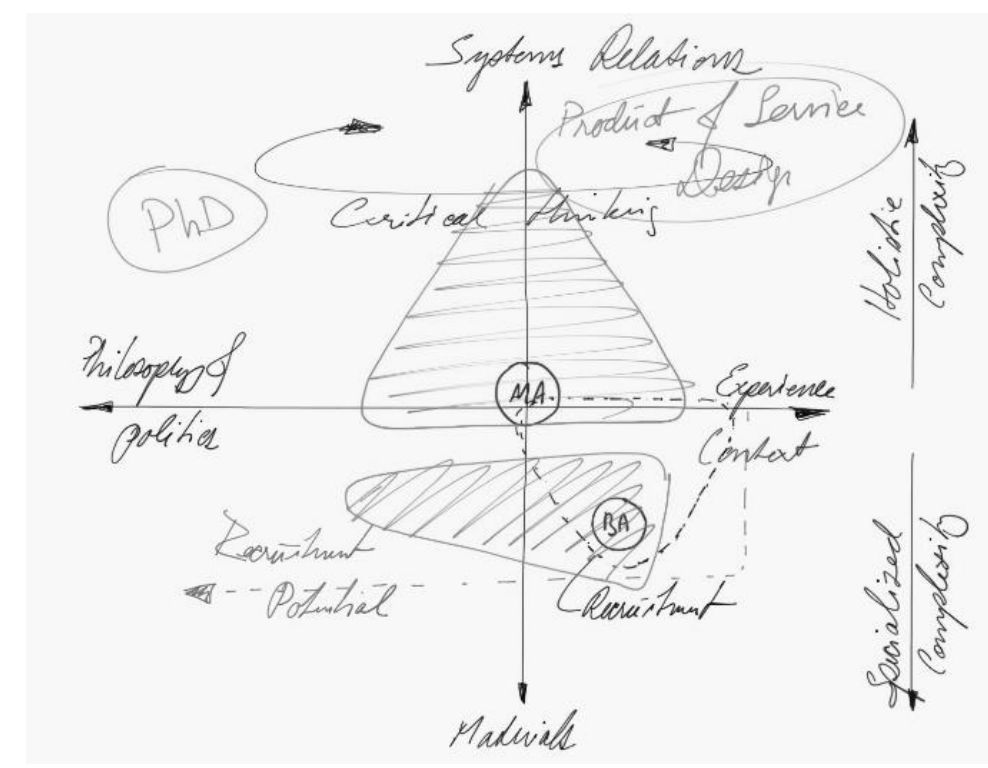

Figure 1. Existing (red circles) and proposed (yellow triangles) bachelor (BA) and masters (MA) design programmes at OsloMet as they relate to the four dimensions (philosophy/politics, materials, experience, and complexity/relations)

The model includes the additional parameter of critical thinking. To explore systems relations beyond previous or existing solutions, students will progress from an initial master-novice training workshop situation on bachelor level to independent thinking and extrovert research during their master study. By meeting with diverse individuals, professions, and researchers, they will develop the skills of selfreflection in relation to values and character and the ability to apply new knowledge and methods to real-life work situations.

\section{SYSTEMS-ORIENTED DESIGN AND THEORY: HOW IT SUPPORTS THE DESIGN PROFESSION AND DESIGN EDUCATION}

Although design education involves some teaching in relation to the potentials and consequences of design - not just for sales but also for use, making, recycling, waste, and emotional and social issues, the overall emphasis has been on exploration and explanation of phenomena "by reducing them to an interplay of elementary units which could be investigated independently of each other;" in parallel with other disciplines that are "mutually independent and largely unaware of each other" [8], design education research and teaching aims to contribute to a better society. The concept of general systems theory offers a cross-disciplinary platform for studying the relations between all of these elements and their influence on behaviour, nature, and society [8], [9]. However, systems theory has rarely featured in design education. As a consequence, designers tend to create services and products without knowing their effect on society and nature or their chances of being implemented, even though several researchers such as Manning (as early as 1967) have noted the interrelation among all elements and constituents of society. These essential problems, issues, policies, and programmes must always be considered and evaluated as interdependent components of an overall system [8-10].

The emerging question, then, is how to develop an approach to design education that provides the knowledge and skills students need if they are to create products and services for the systems in which they must perform.

\subsection{Functioning systems}

To address this question, we looked to systems theory for an understanding of how systems function. In this regard, Meadows and Wright describe three key system qualities: resilience, self-organisation, and hierarchy [4]. Resilience is understood as adaptability, as opposed to rigidity and the "loss of resilience can come as a surprise, because the system usually is paying much more attention to its play than to its playing space. One day it does something it has done a hundred times before and crashes" [11]. This loss of resilience is typical of design education where the educator focuses on their own understanding of reality and ideology to control and run a programme rather than on the context in 
which design and designers must perform. In contrast, resilience is characterised by multiple feedback loops (subsystems) that restore a super-system, bouncing it back into shape or changing it when stretched or perturbed. This involves abilities such as rapid recovery of physical and mental strength. In an educational setting, this can be described as the ability to adapt and change, responding to external or internal pressure without changing the super-system. Meta-resilience systems emerge when feedback loops restore the feedback loops that restore the super-system. These meta-resilience loops restore the feedback loops that restore the system's organisation and, by extension, the meta-meta resilience systems [11] that "...learn, create, design and evolve ever more complex restorative structures" [11]. When meta-resilience emerges, the super-system becomes not only resilient but selforganising or autopoietic - that is, produced by its own system, as for example when a plant uses its own cells to reproduce its own cells [12]. Autopoietic processes are therefore ontogenetic, in that structural change occurs without loss to the underlying organisation [13]. In the same way, education systems can radically change their functioning and their basis for learning within the system described in the EU's Bologna agreement. This autopoietic function is found in both minor and major systemsfor example, in workshops in a design institute, or in the emergence of a new education programme, or in the European education system as a whole. However, we often fail to understand or notice the capacity or properties of autopoietic systems around us - even those we form part of as individuals. For autopoiesis to emerge in design education, one must plan for the autonomy, perturbation, and disorder that promotes wondering rather than clinging to productivity and stability $[14,15]$. Describing the characteristics of hierarchy in self-organising systems, Meadows (2009) explained these in terms of the degree of relational bonding within and between subsystems. When the bonds within a subsystem are stronger than links to other systems, a new system may emerge from the core, coupling with other subsystems over time. Accordingly, autopoietic functions relate to the strength of fixation of relations within and between subsystems. For example, a subsystem may emerge or change for a particular local purpose or function, in turn influencing other subsystems. In extreme instances, small subsystems that function but cease to contribute to the super-system may initiate the collapse of the whole. When a subsystem begins to dominate at the expense of the larger system, sub-optimisation ensues. On the other hand, central control may also create problems by preventing subsystems from exploring and creating as all resilient and autopoietic systems do. In the case of design education in its current form, some sub-systems like workshop facilities and related courses have emerged and begin to dominate at the expense of the economy and capacity of the super-system - the department. As another example, the emergence of systems-oriented design methods has initiated a change in the rules of our programmes and, by implication, future learning for many students.

\subsection{Systems-oriented design}

The inclusion of systems theory in design education has however introduced a perturbation factor: the method of systems-oriented design (SOD) [11]. SOD is a multi- and transdisciplinary platform for research, exploration, analysis, and design. In this context, the designer functions by developing the ability to think in terms of systems by visualising the complex contexts in which products and services must perform. They must therefore be able to identify tensions in subsystems or feedback loops that influence balance, imbalance, coupling, change, emergence, and collapse in the various systems. This thinking depends on the ability to visualise existing, historical, and possible future systems. As a major factor in systems understanding, visualisation enables all stakeholders to see, follow, discuss, contribute to, and influence the project, creating the information simultaneously and continuously as a group [14-18]. This shared work produces much more information than individuals reading reports to a meeting.

\section{THE SKELETON OF A NEW PROGRAMME: "DESIGN IN COMPLEXITY"}

To summarise this ongoing process, we conclude with an analysis of our work on resilience, selforganisation/autopoiesis, and hierarchy. First, when design education engenders autonomy, perturbation, and disorder, it enhances the emergence of autopoietic processes. This runs contrary to the fixed platform that typifies most design education today. If the theory, methods, and expected learning outcomes engender strong bonds within subsystems of self-organisation, the programme will produce change. This does not mean that self-organisation happens within the institution; on the contrary, autonomy, perturbation, and disorder, typically promote coupling with other subsystems in industry, hospitals, biology departments, and so forth. This coupling with other subsystems happens 
through self-organisation and not because programme planners caused it to happen. This change of emphasis orients design education toward exploration of the playing space (complex systems and contexts in society and nature) rather than play or existing practices [11]. This allows students to gain different perspectives on the enhancing dimensions; for example, a design task can be analysed by searching for relevant or non-existing feedback loops that could or should form part of a new design to prevent problems or create new solutions or contexts, so facilitating new understandings of design and its practice. In this way, design students become wiser-or systems-literate-in addressing the complex contexts in which they perform [2]. By working with systems, students will learn to describe the "relationship between structure and behaviour" [11], focusing on how system elements interact to produce an effect that differs from any element alone in a way that "persist a variety of circumstances" [11]. This moves away from the traditional emphasis on improving or changing the performance of the individual parts, which does not necessarily improve or influence the performance of the system as a whole [4], [9], [19]. Students will learn to change behaviours by changing the system rules, in turn changing attitudes or culture [6]. Meadows and Wright's distinction between system, structure, and behaviour is fruitful as a way of understanding this situation and in further analysing and altering systems to explore these relationships. Structure is what makes a functioning system possible, and everything that the system uses defines the structure [14]. The system, or the relationships between structure and behaviour, can be understood as communication. In this way, systems theory describes the relations between dimensions, perspectives, objects, elements, reactions, and experiences in complex contexts, and systems-oriented design uses theory to analyse and create by visualising the complexity that systems theory illuminates.

On that basis, we developed a sketch for the education programme we call Design in Complexity (Figure 2). Here, students will explore without the influence of ideologies, which will instead be introduced in the course Philosophy and Design Research. In completing this course, they may also develop or identify their own existing ideology, and this in itself may influence their future work; as noted earlier, most educators themselves are unaware of the ideologies or certainties or assumptions that inform their work. During this course, students will be introduced to systems theory and its application to systems-oriented design. By extension, they will work within the context of sustainable design in all its complexity. The method of visualising complexity will be introduced and practiced by students during the course, with an additional emphasis on inclusive design processes, collaborative design, and collaborative information creation with other stakeholders [15].

A further course introduces play systems that can be implemented to engage people in the systems they design. They will then prepare for their final thesis in Service Design, Systemic Design II. The pedagogical principles for all courses will be oriented toward problem-based workshop learning. In this way, lectures are kept to a minimum, enhancing the student's responsibility for their own learning.

\section{CONCLUDING THOUGHTS}

In describing a new basis for understanding quality and context in design education, we seek to develop a completely new approach to design education based on general systems theory. Our main argument is that rather than developing a new master's education in design within the existing system, institution, or discipline, we have shifted the perspective from an internal focus on knowledge, ideology, tradition, and capacity to the context in which the designer works. A number of decisions and principles emerge from this theoretical discussion. First, students are afforded an opportunity to acquire knowledge, methods, and skills that will ensure their ability to work holistically in complex contexts. Secondly, education should be designed to accommodate continuous change, not only by connecting to subsystems such as technology or other disciplines but from within. Finally, this requires students to become systems-literate designers, with flexible tools that support research, analysis, and creation of systems, services, and products. 


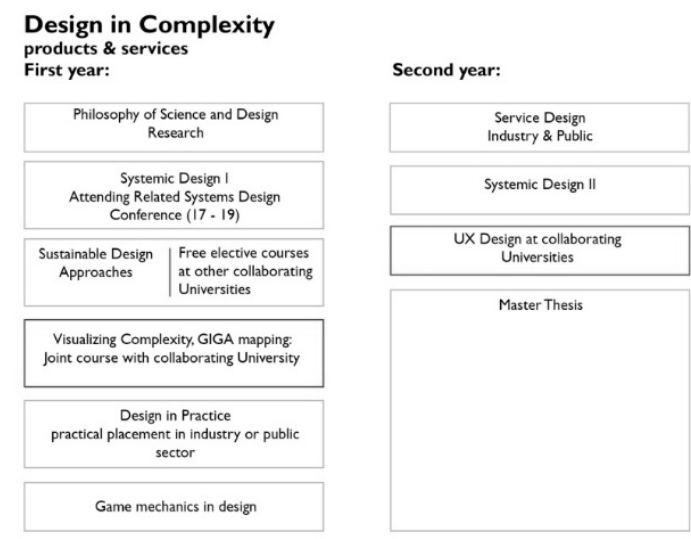

Figure 2. A sketch of the study programme. Based on systems theory and the complex contexts in which students will perform, the aim is to facilitate emergence, experimentation, and disorder to educate systems-literate designers

\section{REFERENCES}

[1] Sevaldson B. and Jones P. Emerging contexts for systems perspectives in design: Relating Systems Thinking and Design 2013 Symposium proceedings: Arkitektur- og designhøgskolen i Oslo; 2013.

[2] Bunnell P. Dancing with Ambiguity. American Society for Cybernetics. 2015;22(4):101-12.

[3] Bunnell P. Dancing with Ambiguity. Cybernetics and Human Knowing. 2015;22(4):101-12.

[4] Meadows DH, Wright D. Thinking in systems: a primer. White River Junction, Vermont: Chelsea Green Publishing; 2015.

[5] Varela F.G., Maturana H.R. and Uribe R. Autopoiesis: The Organisation of Living Systems, Its Characterisation and a Model. Facets of Systems Science. International Federation for Systems Research International.7: Springer US; 1991. p. 559-69.

[6] Meadows D. Leverage Points: Places to Intervene in a System Hartland. VT. USA; 1999.

[7] Sevaldson B. Relating Systems Thinking \& Design 2013. Emerging Contexts for Systemic Design. FORMakademisk. 2013;6(1).

[8] Bertalanffy Lv. General system theory: foundations, development, applications. New York: George Braziller; 1968.

[9] Ackoff R.L. Editor On Passing Through 80. Russel L Ackoff and the Advent of Systems Thinking; 1999; Villanova, PA, USA: Villanova University.

[10] Manning E.C. Political realignment; a challenge to thoughtful Canadians. Toronto: McClelland and Stewart; 1967.

[11] Meadows D.H. and Wright D. Thinking in systems: a primer. London: Earthscan; 2009.

[12] Birger S. and Alex J.R. Relating Systems Thinking and Design I. Practical Advances in Systemic Design. FORMakademisk. 2014;7(3).

[13] Seidl D. Luhmann's theory of autopoietic social systems Münchner betriebswirtschaftliche Beiträge Munich Business Research 2004.

[14] Maturana H.R. and Varela F.J. The tree of knowledge: the biological roots of human understanding: Shambhala; 1987.

[15] Luhmann N. Introduction to Systems Theory: Wiley; 2012. 421 p.

[16] Gulden T. Engagement by lamination of autopoietic concentric interaction systems in games: A study of football and Pokémon GO Human Technology. 2018;14(1):96-134.

[17] Maturana H.R. The organisation of the living: A theory of the living organisation. International Journal of Man-Machine Studies. 1975;7(3):313-32.

[18] Tangen J.O. Hvordan er idrett mulig? skisse til en idrettssosiologi: Høyskoleforlaget; 2004.

[19] Perinbanayagam R. Games and Sport in Everyday Life, Dialogues and Narratives of the Self 2006. 